\title{
Experimentos de Campo em Comportamento Prosocial: Sexo, Densidade e Grupo Cultural ${ }^{1}$
}

\author{
Ronaldo Pilati $^{2}$ \\ Fabio Iglesias \\ Bárbara Requião de Lima \\ Carolina Vieira de Simone \\ Universidade de Brasília
}

\begin{abstract}
RESUMO - A civilidade é um comportamento prosocial ${ }^{3}$ regulado por normas sociais tácitas. No entanto, poucos estudos dedicaram-se aos fatores determinantes da civilidade em contextos urbanos. O objetivo deste trabalho foi testar a influência do sexo, da densidade de transeuntes e da categorização social sobre a civilidade. Foram realizados três experimentos de campo que emularam situações sociais corriqueiras. Os resultados indicaram frequência de ajuda geral superior a $65 \%$. O Estudo 1 indicou a influência do sexo do experimentador e da densidade de transeuntes sobre a civilidade. Os estudos 2 e 3 não forneceram evidências para a hipótese de um favoritismo endogrupo, tal como previsto por teorias de identidade social. Discutem-se as implicações teóricas e práticas desses resultados para a civilidade.
\end{abstract}

Palavras-chave: comportamento prosocial; categorização social; densidade do ambiente; sexo.

\section{Field Experiments of Prosocial Behavior: Gender, Density and Cultural Group}

\begin{abstract}
Civility is a prosocial behavior regulated by tacit social norms. However, few studies have investigated the factors determining civility in urban contexts. The purpose of this paper was to test the influence of gender, pedestrian density, and social categorization on civility. Three field experiments simulated everyday social situations. Results showed an overall help frequency above $65 \%$. Study 1 revealed that civility is influenced by the gender of the researcher and density of pedestrians. Studies 2 and 3 found no support for an endogroup favoritism hypothesis, as predicted by social identity theories. The theoretical and practical implications of theses findings for civility are discussed.
\end{abstract}

Keywords: prosocial behavior; social categorization; environment density; gender.

O estudo da civilidade, a partir da compreensão de quais são os fatores determinantes para a conduta prosocial, é um tema relevante e consistente com a necessidade de se produzir conhecimento empírico e teórico sobre a cultura nacional e a psicologia social do brasileiro. O comportamento prosocial é um tema clássico da psicologia social e foi objeto de investigação de uma grande quantidade de pesquisas a partir

1 Os autores agradecem Aline Spezia Silva, Maíra Guimarães Campos Belo e Moema Fontes Silva Lima pela concepção e coleta de dados do Estudo 1. Zohrah Zanjani inspirou a investigação da variável cultural dos estudos 2 e 3 e participou da coleta de dados com Rino Pereira.

2 Endereço para correspondência: Laboratório de Psicologia Social, Departamento de Psicologia Social e do Trabalho, Campus Darcy Ribeiro, Universidade de Brasília. Brasília, DF. CEP 70.910-900. Email:rpilati@unb.br.

3 Neste texto optamos por redigir o nome do conceito central do artigo desta forma, ao invés de fazer uso da recomendação ortográfica em língua portuguesa - pró-social. Essa escolha foi motivada por dois fatores principais: (a) a necessidade de aproximar o termo da redação em língua inglesa, o que facilita a localização deste artigo em buscas na internet e nas bases de dados internacionais nas quais esta revista está indexada; (b) o propósito de sugerir o uso do termo à comunidade acadêmica como estratégia para nomeação técnica do fenômeno em língua portuguesa, o que traria vantagens de indexação de trabalhos científicos para o campo de investigação do comportamento prosocial. da década de 1960 (Batson, 1998). O questionamento sobre que fatores determinam comportamentos de civilidade, cooperação e suporte a outras pessoas em diversos contextos sociais continua sendo foco de pesquisa. Esse tema é atual, à medida que uma grande pressão e demanda social são realizadas por organizações governamentais e não-governamentais sobre a necessidade de uma conduta cooperativa e solidária dos cidadãos. No Brasil e em outros países, campanhas publicitárias (e.g., Fundação para uma vida melhor) e ações sociais, patrocinadas por diferentes setores, enfatizam a necessidade da civilidade e da conduta socialmente responsável. A adoção desses comportamentos frequentemente é influenciada pelas características da situação social (Moser \& Corroyer, 2001), como o número de pessoas envolvidas e os estereótipos grupais.

Comportamento prosocial é definido como qualquer ato que beneficie a uma pessoa ou grupo, considerado, por uma parcela significativa da população, como uma ação de benefício e ajuda (Batson, van Lange, Ahmad \& Lishner, 2003; Dovidio \& Penner, 2001; Penner, Dovidio, Piliavin \& Schroeder, 2005). Recentemente, a modelagem teórica multinível tem contribuído para o avanço da teoria sobre a psicologia social do comportamento prosocial. Dovidio, Piliavin, Schroeder e Penner (2006) apresentam uma perspectiva abrangente para 
a compreensão desse fenômeno, quando integram o atual estágio teórico da área em uma modelagem de múltiplos níveis de análise. Como micronível de análise os autores pontuam os fatores evolutivos (genéticos) e intraindividuais como determinantes do comportamento prosocial. Como mesonível de análise, apresentam os aspectos de relações interpessoais e das situações sociais onde ocorre a necessidade de ajuda, como normas sociais e contextos urbanos. Como macronível de análise, pontuam os elementos organizacionais e sociais como determinantes, que funcionam como indicadores de condutas socialmente desejadas. Dentro desse último nível de análise encontram-se uma série de desenvolvimentos teóricos sobre o voluntariado em atividades prosociais de longa duração.

Cabe ressaltar que uma perspectiva transcultural também é relevante na pesquisa do comportamento prosocial. Estudos que comparam o comportamento de ajuda em diferentes culturas apontam que a cultura exerce um efeito moderador entre a ajuda e diferentes variáveis antecedentes (Kemmelmeier, Jambor \& Letner, 2006; Knafo, Schwartz \& Levine, 2009; Van de Vliert, Huang \& Levine, 2004). A investigação mais abrangente identificada na literatura, em termos de comparação transcultural, foi apresentada por R. V. Levine e cols. (2001). Os autores compararam o comportamento de ajuda de pedestres em 23 regiões metropolitanas de um mesmo número de países em quatro continentes. Eles encontraram que a taxa de ajuda variou significativamente entre as cidades e o Rio de Janeiro obteve o mais alto índice de ajuda (93\% contra 40\% de Kuala Lampur, capital da Malásia, com a menor taxa). Este resultado instigante traz à tona o questionamento do que caracteriza o brasileiro como um povo solidário. Cientistas sociais já apresentam argumentos dessa característica do brasileiro (Almeida, 2007), mas ainda é necessário o desenvolvimento de estudos nacionais sobre o assunto, com o uso de diferentes estratégias metodológicas, para se compreender essa categoria de comportamentos.

Um elemento central para o avanço da teorização sobre comportamento prosocial diz respeito à definição do fenômeno e às múltiplas facetas que este pode assumir. O presente trabalho parte do pressuposto de que o comportamento de ajuda insere-se nesse campo conceitual como um comportamento regulado por normas sociais aplicadas aos indivíduos. Uma vez que muitas pesquisas em psicologia social tendem a limitar o comportamento de ajuda, associando-o a situações em que a necessidade de ajuda é emergencial, adota-se aqui a posição de que existe uma grande variedade de comportamentos que podem ser categorizados como ajuda.

Pearce e Amato (1980) propuseram um sistema de classificação de comportamentos prosociais, com base nos estudos da psicologia social. Por meio do escalonamento multidimensional, os autores categorizaram 62 situações de ajuda em três grandes dimensões: (1) da ajuda espontânea-informal à ajuda planejada-formal; (2) da ajuda séria à ajuda não-séria; e (3) da ajuda direta à ajuda indireta. Essas categorias corresponderiam respectivamente ao contexto social em que a ajuda é oferecida, ao grau de necessidade de ajuda e ao tipo de ajuda oferecida. Tal categorização é relevante neste trabalho, que analisa a influência de determinadas variáveis na disponibilidade comportamental dos indivíduos de ajudarem outras pessoas em uma situação específica, caracterizada como menos séria e mais espontânea. O objetivo aqui, portanto, será o de analisar o comportamento de ajuda em uma situação em que estranhos devem interagir de modo a preservar normas tácitas que regulam as trocas sociais cotidianas.

No que diz respeito a essas normas, Moser e Corroyer (2001) pontuam que há comportamentos específicos, observados em contextos diversificados, que demonstram padrões de civilidade e boa convivência social. Os autores definem civilidade como "regras tácitas que governam comportamentos sociais que regulam as interações sociais" (p. 612). Normas de conduta social são antecedentes importantes de diferentes categorias de comportamentos prosociais (Batson, 1998; Batson \& cols., 2003; Dovidio \& Penner, 2001; Penner \& cols., 2005), pois definem formas de agir que são socialmente desejáveis e que funcionam como elementos de estruturação das relações sociais. Assim, dentro do conjunto de comportamentos prosociais estão contidas dimensões de civilidade, gentileza e polidez nas relações interpessoais.

O presente artigo foca o estudo das normas de civilidade no comportamento de ajuda, uma vez que trata da identificação dos determinantes de situações de ajuda entre pessoas estranhas, típicas daquelas encontradas em grandes cidades, nas quais pessoas que não se conhecem interagem. As situações de ajuda criadas neste trabalho estariam enquadradas nessa dimensão da civilidade como atos de natureza desinteressada, necessárias à boa convivência social. É importante enfatizar que o comportamento prosocial não se restringe à civilidade, mas refere-se a um grande conjunto de comportamentos, dirigidos a outras pessoas ou grupos e que são considerados benéficos por uma parcela significativa da população (Batson \& cols., 2003). Este trabalho cria situações que emulam normas tácitas de conduta; portanto, é a comportamentos expressivos de civilidade que ele se refere. Comportamentos prosociais motivados por sentimentos de empatia e solidariedade (Batson, 1998) não são foco deste estudo. Esses comportamentos guardam antecedentes e diferenças conceituais significativas com os comportamentos de civilidade. O que se argumenta é que comportamentos de civilidade são um dos tipos de comportamentos prosociais.

Uma das preocupações frequentes da literatura sobre comportamento prosocial diz respeito à influência do contexto urbano sobre a civilidade das relações humanas. $\mathrm{O}$ padrão de interações nesse contexto influencia os indivíduos, trazendo efeitos significativos para a conduta socialmente desejável nas interações sociais. Há várias décadas, Milgram (1970) já apresentou evidências sobre a hipótese da sobrecarga urbana, na qual a grande quantidade de pessoas em trânsito levaria a uma sobrecarga de estímulos sociais, diminuindo a taxa de comportamento de ajuda e civilidade. Em um estudo observacional, com o objetivo de avaliar as consequências da influência do contexto urbano e da densidade de transeuntes para a civilidade, Moser e Corroyer (2001) analisaram o comportamento de segurar a porta aberta, de um centro comercial, para o próximo pedestre que entra no estabelecimento. Os resultados apontaram diferenças no comportamento dos indivíduos entre duas cidades, Paris e Nantes. Verificou-se maior taxa de comportamento de ajuda nesta última cidade, menos populosa. Além disso, quando avaliado o efeito da densidade imediata, houve diferença significativa apenas em Paris, onde a maior densidade levou a taxas significativamente menores de ajuda. Os autores res- 
saltam que se o participante recebeu ajuda do pedestre à sua frente, há um aumento significativo da chance dele ajudar o pedestre seguinte. Esse é um achado relevante, que reforça a noção das regras tácitas de civilidade, pois a ajuda prévia pode funcionar como um eliciador do que é socialmente desejável naquele contexto, funcionando como um modelo informativo ou normativo (Cialdini \& Trost, 1998).

No Brasil foram relatadas poucas pesquisas empíricas sobre comportamento prosocial. Silva e Günther (2001) apresentaram um experimento de campo no qual se observou a ajuda entre passageiros de ônibus com itinerários dentro da cidade de Brasília e de ônibus que conduziam à sua periferia. O comportamento observado era a oferta de ajuda de passageiros sentados para carregar livros do experimentador sem assento. Os resultados mostraram que mulheres e passageiros da linha da periferia tenderam a ajudar mais ao experimentador. Em outro estudo, Silva, Günther, Lara, Cunha e Almeida (1998) realizaram um delineamento fatorial quase-experimental com o uso da técnica da carta perdida. $\mathrm{O}$ comportamento de ajuda era depositar a carta em uma caixa ou agência dos correios. Não foram observadas diferenças significativas de ajuda para grupos sociais distintos (i.e., negro, homossexual ou controle), mas a possibilidade de contatar o experimentador via telefone produziu um efeito significativo, levando a um maior comportamento de ajuda, o que indica o efeito positivo do contato e da proximidade social com aquele que necessita de ajuda como um fator relevante na decisão em ajudar. Silva e Günther (1999) conduziram outro experimento de campo, por meio do uso da técnica telefônica do número errado. Os autores desenvolveram uma história-problema, na qual solicitavam que o participante da pesquisa fizesse uma ligação telefônica para o experimentador. Foram analisados os efeitos do gênero do experimentador, proximidade de moradia, local de moradia (periferia ou zona central) e forma de residência (apartamento ou casa) sobre o comportamento de ajuda. Houve uma taxa de $39 \%$ de ajuda e apenas o fato de a experimentadora ser mulher indicou diferença significativa, tendo sido mais auxiliada.

Tais pesquisas são importantes por serem brasileiras e por indicarem que variáveis da situação e do indivíduo que necessita de ajuda influenciam o comportamento prosocial. Diante destas evidências empíricas, faz-se necessário testar esses e outros antecedentes da ajuda em situações experimentais diferenciadas. Estudos sobre comportamento prosocial, com delineamento experimental e conduzidos em ambientes naturais, podem dar respostas eficientes sobre os antecedentes desse fenômeno, mas possuem evidentes limitações inerentes ao método. Em pesquisas com delineamento experimental, nas quais não se tem informação sistematizada sobre a percepção do participante, não é possível avaliar a interpretação do sujeito crítico sobre a situação social, nem se observar fatores processuais relativos ao comportamento de civilidade. Essa é uma limitação típica de estudos deste tipo, mas assumida neste trabalho, pois aqui busca-se produzir evidências empíricas em ambientes naturais sem perder de vista a validade interna que estudos experimentais possibilitam para o teste de hipóteses de fatores antecedentes.

O aprimoramento das relações intergrupais é uma das grandes preocupações da psicologia social. Neste contexto, inserem-se investigações que refletem a ideia de que a categorização social, por mais heurística que seja para a compreensão de determinados aspectos da realidade, pode causar a acentuação das diferenças entre grupos, funcionando como um moderador para a projeção social. O processo de projeção social faz com que as pessoas apresentem a tendência de superestimar o compartilhamento de valores e ideias dentro de seu próprio grupo, construindo a percepção de uma identidade comum, e de subestimar as suas semelhanças com alguém de um grupo externo, devido à percepção de que entre os grupos existiria uma maior distância social (Robbins \& Krueger, 2005). Alguns estudos têm apontado que existe um favoritismo dos membros do endogrupo em prestar ajuda mais frequentemente a membros categorizados de seu grupo do que para membros do exogrupo (M. Levine, Prosser, Evans \& Reicher, 2005; Stürmer \& Snyder, 2010; Stürmer, Snyder, Krop \& Siem, 2006; Stürmer, Snyder \& Omoto, 2005). Em geral, essas pesquisas têm sido feitas em ambientes laboratoriais e não foram identificados estudos brasileiros que apresentassem relatos do efeito que a categorização social tem sobre situações urbanas corriqueiras de ajuda. Por esse motivo, considera-se relevante a busca de evidências empíricas sobre o efeito que a categorização social possui sobre a civilidade. Nesse marco teórico, pressupõe-se que categorizar um indivíduo como semelhante aumentará a chance de ajudá-lo em situações corriqueiras. Essa compreensão teórica será testada neste trabalho.

Nesse contexto, este trabalho tem como objetivo, avaliar o impacto que: (a) o sexo de participantes e experimentadores; (b) a densidade de transeuntes; e (c) a vestimenta identificadora de grupo cultural têm sobre um tipo de comportamento de civilidade. Para tal, foram realizados três experimentos de campo, utilizando o paradigma experimental de simulação de uma situação de ajuda em um ambiente natural (R. V. Levine, Martinez, Brase \& Sorenson, 1994; R. V. Levine \& cols., 2001; R. V. Levine, Reysen \& Ganz, 2008; Milgram, 1970; Silva \& Günther, 2001). Assim, os três estudos avaliaram o comportamento de civilidade por meio da observação do comportamento dos indivíduos sem que estes tomassem conhecimento da situação. Como forma de aumentar o realismo dos experimentos, foram desenvolvidas situações de ajuda corriqueiras para os locais de coleta de dados. Todos os estudos foram realizados nos mesmos ambientes urbanos: (a) um centro comercial com cerca de 200 lojas e aproximadamente 50.000 transeuntes por dia; e (b) um campus universitário, que conta com cerca de 5.000 transeuntes por dia. As coletas foram realizadas tanto nos fins de semana quanto durante a semana e em horários variados - procurou-se apenas evitar horários de movimento exagerado ou muito reduzido.

\section{Estudo 1}

Considerando os fatores situacionais antecedentes do comportamento de civilidade (i.e., sexo do experimentador, sexo do participante e densidade de transeuntes), este estudo teve como objetivo testar a influência dessas variáveis sobre o comportamento de civilidade. Considerando a hipótese do custo pessoal em ajudar (Dovidio \& Penner, 2001), emulouse uma situação de custo moderado para o participante da pesquisa. 


\section{Método}

\section{Participantes}

Foram realizadas 117 situações experimentais, distribuídas em quatro condições experimentais, variando-se o sexo do experimentador e da pessoa-alvo. No total, participaram do experimento 60 homens e 57 mulheres, com idade estimada entre 18 e 30 anos. O experimento não foi realizado com pessoas acompanhadas, gestantes, idosas, ou com crianças no colo.

\section{Instrumento e materiais}

Elaborou-se um protocolo de observação para avaliar o comportamento de ajuda e as variáveis do ambiente, como a densidade do local e o sexo das pessoas-alvo. Os materiais utilizados foram um caderno, óculos escuros, fones de ouvido, casaco e livro (objeto derrubado no chão).

\section{Variáveis}

A variável dependente dos três estudos do presente artigo foi o comportamento de ajuda. No caso deste primeiro estudo, tendo em vista que o objeto derrubado foi um livro, considerou-se ajuda o ato de o participante abaixar para pegálo no chão e entregá-lo ao experimentador (ajuda completa); ou então o ato de o participante tocar o experimentador, apontando-lhe o livro caído (ajuda física). Considerandose que o experimentador não respondia a contatos verbais, somente reações de contato físico foram consideradas como ajuda. Assim, o comportamento foi classificado como de nãoajuda quando o indivíduo ignorava o livro caído no chão ou, então, quando simplesmente chamava o experimentador, sem estabelecer qualquer contato físico. As variáveis independentes escolhidas foram: (a) densidade do ambiente (alta e baixa, aferida pelos observadores), e (b) sexo do participante e do experimentador.

\section{Procedimento}

A situação experimental criada consistia em deixar cair um livro na frente do participante da pesquisa, de forma que ele percebesse a "perda desatenta" do objeto. O experimentador andava em ritmo normal, em linha reta, e deixava o livro cair a uma distância aproximada de 1 metro à frente do participante, que vinha em direção oposta. Simulando não ter percebido a queda do livro, o experimentador continuava a caminhar sem olhar para trás, ainda que o participante o chamasse diversas vezes. Foram escolhidas pessoas sozinhas como participantes, de modo a evitar a influência que um acompanhante poderia exercer no sentido de compelir a ajuda ou inibi-la.

Durante a situação experimental, o experimentador, ora homem ora mulher, carregando um caderno e um casaco, usou fones de ouvido, simulando escutar música alta num rádio portátil para dificultar a comunicação entre o experimentador e o participante, e óculos escuros, para evitar o contato visual. Essa caracterização de dificuldade de contato simulava o aumento do custo da ajuda para o participante, pois este deveria apanhar o livro e carregá-lo até o experimentador para efetuar a devolução.

A situação foi planejada, portanto, para que o experimentador aparentasse estar pouco acessível e razoavelmente isolado de contatos verbais com a pessoa-alvo, exigindo dela um maior esforço para devolver o objeto caído. Os dois observadores registraram as reações, procurando não interferir no contexto da situação de coleta. As simulações experimentais foram realizadas em locais que proporcionassem um bom fluxo de passagem. Imediatamente depois da simulação, os observadores discutiam e acordavam sobre as anotações feitas, incluindo a aferição da densidade do ambiente. Apenas as situações nas quais havia concordância foram aproveitadas no estudo.

Foram realizadas 15 sessões experimentais piloto no campus universitário e 15 no centro comercial, com o objetivo de testar o protocolo de coleta de dados e o procedimento. Foram realizadas pequenas alterações no protocolo, visando maior precisão da anotação das informações no momento da coleta de dados, proporcionando maior facilidade e rapidez no registro das reações dos participantes. Essas sessões também serviram para verificar a densidade dos locais nos horários da coleta, o fluxo de passagem e o comportamento dos experimentadores.

\section{Resultados}

Os resultados do Estudo 1 são apresentados na Tabela 1, considerando os totais por categoria.

Foram realizados testes de qui-quadrado para avaliar o nível de diferença entre as variáveis. Considerando-se os dados agrupados, de um total de 117 oportunidades de ajuda observadas, obteve-se ajuda em $68 \%$ das vezes. A partir do cruzamento das variáveis local e comportamento de ajuda, verificou-se que, no campus universitário, a frequência de ajuda foi significativamente maior do que no centro comercial $\left(\chi^{2}=3,91 ; p<0,05\right)$. A alta densidade do ambiente gerou frequências de ajuda significativamente menores do que em ambientes mais vazios $\left(\chi^{2}=7,48 ; p<0,05\right)$. Diferenças na ajuda em função do sexo foram encontradas somente quando a pessoa-alvo do experimento era homem. De acordo com os dados, os homens tenderam a ajudar mais outros homens do que as mulheres $\left(\chi^{2}=3,78 ; p=0,05\right)$.

A partir desses resultados, considerou-se necessário realizar um segundo estudo, mantendo como variável independente a densidade do local, mas variando o processo de identificação do grupo de pertencimento social daquele que apresenta a necessidade de ajuda, com o propósito de testar a hipótese da identidade social.

\section{Estudo 2}

No segundo experimento, utilizou-se uma situação de ajuda ligeiramente parecida, porém, manteve-se constante $o$ sexo do experimentador, que foi sempre mulher, e variou-se a vestimenta do mesmo, de forma a se testar a hipótese da 
Tabela 1. Frequências de ajuda e não ajuda em função do sexo do experimentador no Estudo 1.

\begin{tabular}{|c|c|c|c|c|c|}
\hline & & \multicolumn{4}{|c|}{ Comportamento de Ajuda } \\
\hline & & \multicolumn{2}{|c|}{ Ajuda } & \multicolumn{2}{|c|}{ Não Ajuda } \\
\hline & & \multicolumn{4}{|c|}{ Condição: Sexo do Experimentador } \\
\hline & & Masculino & Feminino & Masculino & Feminino \\
\hline \multirow{2}{*}{ Densidade } & Cheio & 19 & 15 & 11 & 15 \\
\hline & Vazio & 22 & 23 & 4 & 7 \\
\hline \multirow{2}{*}{ Local } & Campus & 23 & 23 & 7 & 7 \\
\hline & C. Comercial & 19 & 15 & 8 & 15 \\
\hline \multirow{2}{*}{ Sexo } & Masculino & 24 & 19 & 4 & 11 \\
\hline & Feminino & 18 & 19 & 11 & 11 \\
\hline Total & & 42 & 38 & 15 & 22 \\
\hline
\end{tabular}

influência da categorização do grupo social (M. Levine \& cols., 2005; Stürmer \& cols., 2006; Stürmer \& cols., 2005) como antecedente da ajuda. Este estudo objetivou avaliar o impacto (a) da categorização social, (b) do local e (c) do sexo do participante sobre o comportamento de civilidade.

Para se emular a categorização de grupo social foi utilizada uma vestimenta, em uma das condições de pesquisa, que identificava o grupo de muçulmanos. Essa vestimenta foi escolhida por ser de rápida identificação em contexto urbano no qual os dados foram coletados, pois a frequência de pessoas com esse tipo de roupa é muito pequena.

\section{Método}

\section{Participantes}

Participaram do estudo 120 pessoas, sendo 60 homens e 60 mulheres. Do total de participantes, 60 foram abordados no campus universitário e 60 no centro comercial, 30 na condição experimental (i.e., experimentador com vestimentas muçulmanas) e 30 na condição controle (i.e., experimentador com vestimentas casuais - calça jeans e camiseta) em cada um dos locais de coleta de dados. O mesmo critério de seleção dos indivíduos adotado no Estudo 1 foi empregado.

\section{Instrumento e materiais}

Elaborou-se um protocolo de observação, para registro do comportamento de ajuda e sexo dos participantes. Havia ainda espaço para a indicação da condição experimental (trajes casuais ou muçulmanos) e do local da sessão experimental (campus ou centro comercial). Duas experimentadoras revezaram-se no papel da pessoa que necessita de ajuda, vestindo um véu e uma túnica, corriqueiramente utilizados na vestimenta muçulmana feminina, e calças jeans e camiseta como vestimenta casual.

\section{Variáveis}

A variável dependente deste estudo foi o comportamento de ajuda e as variáveis independentes foram o local, sexo do participante e vestimenta de grupo cultural (trajes muçulma- nos $\mathrm{x}$ trajes casuais). Considerou-se ajuda o ato de o participante abaixar para pegar folhas de papel no chão derrubadas pelo experimentador e devolvê-las. Foi classificado como não ajuda quando o indivíduo ignorava as folhas caídas no chão, pedia desculpas e continuava o seu trajeto ou quando simplesmente continuava caminhando.

\section{Procedimento}

A experimentadora caminhava a passos normais e carregava uma pasta com algumas folhas soltas por cima. Ao deparar-se com uma pessoa caminhando na direção contrária, ela esbarrava de maneira proposital no transeunte, derrubando todas as folhas no chão. A estratégia era criar uma situação que exigisse um maior esforço da pessoa-alvo em abaixar-se e ajudar o experimentador a recolher as folhas. Os auxiliares de pesquisa registraram o comportamento dos participantes.

Foram novamente escolhidos somente transeuntes sozinhos. Os observadores registraram as reações a uma distância de aproximadamente 5 metros, procurando não interferir no contexto da situação experimental. A exemplo do primeiro estudo, foram realizados testes-piloto para adequação do protocolo de observação e do procedimento experimental. As devidas adaptações foram realizadas, resultando nos procedimentos descritos.

\section{Resultados}

Os resultados do Estudo 2 são apresentados na Tabela 2. Dentre as 120 oportunidades de ajuda realizadas, observouse que em 87 casos (72,5\%), a ajuda foi recebida. Em uma análise de qui-quadrado para a variável ajuda, observou-se que houve uma diferença significativa $\left(\chi^{2}=24,30 ; p<0,001\right)$, indicando que a taxa de ajuda geral foi significativamente maior do que a de não-ajuda. Os percentuais observados indicam que houve uma maior frequência de ajuda no campus, com $76,6 \%$ contra $68,3 \%$ no centro comercial. Em relação ao sexo, observou-se que $66,6 \%$ dos homens ofereceram ajuda à experimentadora vestida com trajes muçulmanos, enquanto $83,3 \%$ das mulheres a ajudaram.

Também foram realizados testes para se aferir o grau de associação entre ajuda e as variáveis independentes. Não foi observada diferença significativa para a variável trajes do experimentador $\left(\chi^{2}=0,38 ; n s\right)$. O mesmo ocorreu para a 


\begin{tabular}{llcccc} 
& & \multicolumn{2}{c}{ Ajuda } & Não Ajuda \\
\cline { 3 - 6 } & & & \multicolumn{2}{c}{ Condição: Vestimenta } & Casuais \\
\hline \multirow{2}{*}{ Sexo } & Muçulmanos & Casuais & Muçulmanos & 7 \\
& Masculino & 20 & 23 & 10 & 11 \\
\hline \multirow{3}{*}{ Local } & Feminino & 25 & 19 & 5 & 8 \\
\cline { 2 - 6 } Total & Campus & 24 & 22 & 6 & 10 \\
\hline & C. Comercial & 21 & 20 & 9 & 18 \\
\hline
\end{tabular}

variável sexo $\left(\chi^{2}=0,04 ; n s\right)$ e local $\left(\chi^{2}=1,05 ; n s\right)$. No geral, o cruzamento entre estas variáveis indica que nenhuma das variáveis independentes produziu efeito significativo no comportamento de ajuda.

Análises complementares foram realizadas. Quando considerado simultaneamente o comportamento de ajuda e a condição de vestimenta do experimentador, não foram observadas diferenças significativas entre local e vestimenta para aqueles que ajudaram $\left(\chi^{2}=0,008 ; n s\right)$ e para os que não ajudaram $\left(\chi^{2}=0,07 ; n s\right)$. Não houve diferença significativa em função do sexo e do uso de trajes para aqueles que ajudaram $\left(\chi^{2}=0,93\right.$; ns $)$ nem para os que não ajudaram $\left(\chi^{2}\right.$ $=2,53$; ns).

Uma possível hipótese explicativa para os resultados do Estudo 2 é relacionada ao tipo de situação de ajuda criada, pois o esbarrão implica em um maior envolvimento do participante da pesquisa como 'responsável' pelo ocorrido, o que pode explicar a alta taxa de ajuda independentemente da condição experimental. Além disso, o fato de haver possibilidade de contato visual e auditivo entre participante e experimentador facilitaria a diminuição do 'embaraço' criado pela situação. Se, por um lado, haveria um custo maior na tarefa de ajuda, pois o participante deveria pegar várias folhas espalhadas no chão, por outro não exigiria que a pessoa saísse de seu caminho para alcançar o experimentador.

Por esses motivos, considerou-se necessário realizar um terceiro estudo, por meio da geração de uma situação experimental que possibilitasse eliciar um comportamento de ajuda que não sugerisse uma parcela de culpa do participante da pesquisa, bem como dificultando o contato pessoal da pessoa-alvo com o experimentador. Considerou-se que a hipótese da categorização social deveria ser mais bem explorada, por meio de outra situação experimental. Para tanto, este estudo utilizou a mesma situação do Estudo 1, mas com as variáveis independentes do Estudo 2, incluindo também a variável densidade do ambiente.

\section{Estudo 3}

Este estudo teve como objetivo testar a influência (a) da categorização social, (b) do sexo do participante, (c) do local, e (d) da densidade de transeuntes sobre o comportamento de civilidade.

\section{Método}

\section{Participantes}

Foram realizadas 134 sessões experimentais, das quais 60 no campus universitário e 74 no centro comercial, 69 na condição experimental e 65 na condição controle. Do total de participantes, 71 eram mulheres e 63 homens. Os indivíduos foram, da mesma maneira que nos estudos anteriores, escolhidos entre transeuntes desacompanhados, sem que eles tomassem conhecimento do experimento.

\section{Instrumento e materiais}

Elaborou-se um protocolo de observação. No protocolo registravam-se, além das variáveis de ambiente presente nos demais - densidade, sexo dos participantes -, dados como expressões verbais e número de passos dados pelo participante, para indicar o custo da ajuda.

O protocolo buscou classificar o comportamento dos indivíduos na situação de ajuda em seis categorias: (a) Não viu o objeto; (b) Não pegou o objeto e chamou o experimentador; (c) Pegou o objeto e caminhou até o experimentador; (d) Viu o objeto, mas não pegou; (e) Pegou o objeto e chamou o experimentador; (f) Pegou o objeto, caminhou até o experimentador e tocou no experimentador.

Para a caracterização das experimentadoras, utilizou-se véu, túnica, calças jeans, camisetas, óculos escuros, celular, aparelho de MP3 com fones de ouvido auriculares com fio e livro com inscrições em idioma persa na capa.

\section{Variáveis}

Considerou-se ajuda o ato de o participante abaixar para pegar o livro e entregá-lo ao experimentador. O comportamento foi classificado como de não-ajuda quando, tendo visto a situação, o indivíduo ignorava o livro caído no chão, ou então quando simplesmente chamava o experimentador, ou até mesmo pegava o livro no chão, sem, no entanto, entregá-lo ao experimentador. As variáveis independentes 
foram: (a) local do experimento, (b) trajes indicadores de contexto cultural (os trajes usados pelas experimentadoras), (c) sexo do participante-alvo, e (d) densidade de transeuntes no ambiente.

\section{Procedimento}

A situação experimental criada foi semelhante à do primeiro estudo. Durante as sessões experimentais estavam sempre presentes uma experimentadora e dois observadores. A experimentadora estava ora trajada com vestimentas muçulmanas, ora com vestimentas casuais. Na condição controle (i.e., vestimentas casuais), a experimentadora usava, ainda, fones de ouvido conectados a um MP3 player que ficava à vista do participante, para dificultar a comunicação, além de óculos escuros. Na condição experimental (i.e., vestimentas muçulmanas), a experimentadora usava óculos escuros, mas simulava uma conversa ao telefone celular, com o mesmo intuito de dificultar a comunicação com o participante, visto que os fones de ouvido não seriam percebidos sob o véu.

A experimentadora carregava uma pasta na lateral do corpo juntamente com um livro, o objeto a ser derrubado. $\mathrm{O}$ livro tinha inscrições em idioma Persa, para facilitar a estereotipização em relação à experimentadora na condição experimental. Na condição controle, o mesmo livro foi utilizado, mas supôs-se que, nesse outro contexto, o participante não atribuiria, a partir do livro com inscrições persas, significado que alterasse os resultados. A pasta foi utilizada para que a experimentadora pudesse derrubar o livro e simular que não tinha percebido que este havia ficado para trás. A exemplo dos estudos anteriores, foram realizados testes piloto para adequação do protocolo de observação e do procedimento experimental. As devidas adaptações foram realizadas, resultando nos procedimentos descritos.

\section{Resultados}

Os resultados do Estudo 3 são apresentados na Tabela 3. Do total de 134 situações experimentais realizadas, observaram-se 107 casos de ajuda, o que representou quase
$80 \%$ do total $\left(\chi^{2}=47,76 ; \mathrm{p}<0,001\right)$. A relação entre ajuda e trajes do experimentador não foi significativa $\left(\chi^{2}=0,82\right.$; ns). Não foram significativas as relações entre: ajuda e local $\left(\chi^{2}=0,22 ; n s\right)$, ajuda e densidade de transeuntes $\left(\chi^{2}=4,22\right.$; $n s)$, e ajuda e sexo $\left(\chi^{2}=1,35\right.$; ns $)$.

Foram realizadas análises complementares. Os testes de qui-quadrado apontaram que não existe diferença significativa em relação ao local da coleta e aos trajes da experimentadora para os indivíduos que não prestaram ajuda $\left(\chi^{2}\right.$ $=0,15 ; \mathrm{ns})$ e nem para aqueles que ajudaram $\left(\chi^{2}=0,78 ; \mathrm{ns}\right)$. Considerando a densidade do local, avaliada pelos auxiliares de experimentação, nota-se que não há diferença significativa para os que não ajudaram $\left(\chi^{2}=2,53\right.$; ns $)$, porém observou-se diferença significativa para os que ajudaram $\left(\chi^{2}=12,88\right.$; $\mathrm{p}<$ $0,001)$, pois houve uma maior taxa de ajuda para a condição de trajes muçulmanos quando a densidade era menor (menos do que cinco pessoas), se comparado aos trajes casuais. Já quando considerado sexo. não foi observada diferença significativa para os que não-ajudaram $\left(\chi^{2}=0,004\right.$; ns $)$ e nem para os que ajudaram $\left(\chi^{2}=0,08 ; n s\right)$.

\section{Discussão Geral}

O objetivo deste trabalho foi avaliar o impacto do sexo do experimentador, da densidade de transeuntes e da vestimenta como fatores determinantes de um comportamento de civilidade no contexto urbano. Considera-se que esse objetivo foi alcançado e os resultados permitiram conhecer determinantes da civilidade do brasileiro em contexto urbano.

Os três estudos realizados indicaram uma alta taxa de ajuda, variando de $68 \%$ (Estudo 1) a $80 \%$ (Estudo 3). Esses valores são expressivos e estatisticamente significativos se comparados ao que se esperaria ocorrer ao acaso. É interessante notar que essa alta frequência de ajuda se assemelha ao que R. V. Levine e cols. (2001) relatam em seu estudo transcultural (i.e., 93\% de ajuda geral para os três comportamentos). Esses resultados parecem indicar que, no geral, o brasileiro é predisposto a oferecer ajuda a desconhecidos em situações urbanas corriqueiras. Também reforçam essa ideia os dados apresentados por Silva e cols. em estudos realizados ao longo da década de 1990 (Silva \& Günther, 2001; Silva

Tabela 3. Frequências de ajuda e não ajuda em função da condição experimental no Estudo 3.

\begin{tabular}{|c|c|c|c|c|c|c|}
\hline & & \multirow{4}{*}{ Densidade* } & \multicolumn{4}{|c|}{ Comportamento de Ajuda } \\
\hline & & & \multicolumn{2}{|c|}{ Ajuda } & \multicolumn{2}{|c|}{ Não Ajuda } \\
\hline & & & \multicolumn{4}{|c|}{ Condição Experimental: Trajes } \\
\hline & & & Muçulmanos & Casuais & Muçulmanos & Casuais \\
\hline \multirow{6}{*}{ Local } & \multirow{3}{*}{ Campus } & $>10$ & 1 & 1 & 0 & 0 \\
\hline & & 5 a 10 & 3 & 3 & 2 & 1 \\
\hline & & $<5$ & 23 & 18 & 2 & 6 \\
\hline & \multirow{3}{*}{ C. Comercial } & $>10$ & 8 & 18 & 0 & 5 \\
\hline & & 5 a 10 & 3 & 11 & 3 & 4 \\
\hline & & $<5$ & 16 & 2 & 4 & 0 \\
\hline \multirow{2}{*}{ Sexo } & Feminino & & 28 & 26 & 7 & 10 \\
\hline & Masculino & & 26 & 27 & 4 & 6 \\
\hline Total & & & 54 & 53 & 11 & 16 \\
\hline
\end{tabular}

* Densidade: $>10=$ mais que 10 pessoas; 5 a $10=$ entre 5 e 10 pessoas; $<5=$ menos que 5 pessoas em uma área de aproximadamente 25 metros quadrados. 
\& cols., 1998). Nos dois casos aqui citados, a taxa de ajuda observada foi alta, também acima dos $60 \%$.

R. V. Levine e cols. (2001) defendem o argumento de que a característica de simpatia das culturas latinas (Triandis, Marín, Lisansky \& Betancourt, 1984) é um fator explicativo dos resultados encontrados em seu estudo. Efetivamente não há como se dar apoio a essa hipótese no presente trabalho, mas os resultados aqui obtidos indicam a necessidade de se compreender melhor a característica solidária do brasileiro por meio de estudos empíricos em psicologia social, pois há muita discussão sobre essa prontidão prosocial em nossa cultura (Almeida, 2007).

Vale ainda uma ressalva sobre a comparação de taxas gerais de ajuda em experimentos de campo realizados no país. É fundamental se ampliar as localidades de coleta de dados, pois à exceção do trabalho de R. V. Levine e cols. (2001), os demais estudos publicados foram feitos em Brasília. Seria importante o estabelecimento de uma agenda de pesquisa que visasse comparar resultados de ajuda a estranhos e outros tipos de comportamentos de civilidade em situações urbanas corriqueiras em outras cidades do país.

Os achados do Estudo 1 indicam que há uma propensão maior de homens a ajudarem homens, o que poderia ser explicado pelo aspecto de proximidade social mais saliente entre transeuntes do mesmo sexo, aumentando a chance de contato social nessa condição. Este resultado também ressalta um possível script de relações sociais, no qual as mulheres tenderiam a aguardar ajuda ao invés de oferecer ajuda. Essa questão de pesquisa precisa ser mais bem investigada nos estudos empíricos de psicologia social.

O Estudo 1 traz uma evidência da influência da densidade do local, pois quanto maior a quantidade de passantes maior a sobrecarga de informação e a difusão de responsabilidade na emissão de um comportamento de ajuda (Milgram, 1970). No concernente à influência da densidade de transeuntes nos estudos 2 e 3, observa-se que não houve o mesmo efeito observado no Estudo 1, pois a taxa de ajuda não foi influenciada por esse fator. Essa ocorrência pode estar associada ao controle do gênero do experimentador, variável que influenciou essa taxa no Estudo 1.

A pesquisa sobre comportamento de ajuda e categorização social tem apontado que há uma tendência a se ajudar mais os indivíduos que pertencem ao mesmo grupo (Dovidio \& cols., 2006; M. Levine \& cols., 2005; Stürmer \& cols., 2006; Stürmer \& cols., 2005). A hipótese da influência da categorização social no comportamento prosocial é explicada pela identidade social dentro de um mesmo grupo, o que provocaria mais sentimentos de empatia e afetividade com aquele que necessita de ajuda. Apesar das considerações iniciais, de que a identificação social com o experimentador poderia levar a comportamentos de ajuda mais frequentes, esse achado não foi confirmado neste trabalho, pois a diferença geral não foi significativa.

Quando se considera a densidade do local na situação experimental, há uma indicação de que existe maior difusão de responsabilidade (Batson, 1998; Dovidio \& Penner, 2001) para os indivíduos de outro grupo social. Houve maior difusão, no Estudo 3, no centro comercial, onde a experimentadora com trajes muçulmanos recebeu menor taxa de ajuda quando havia mais pessoas no ambiente. Pode se interpretar esse resultado da seguinte forma: quando o indivíduo em necessidade de ajuda pertence a outro grupo social, outra pessoa que passa poderia se responsabilizar em ajudar, diminuindo o grau de atribuição pessoal de responsabilidade.

Quando considerada a quantidade de espectadores, não foi observada diferença geral da categorização social. Algumas possíveis explicações para isso podem ser lançadas: (a) a roupa muçulmana não foi suficiente para produzir aspectos de categorização esperados; (b) se, por um lado, o indivíduo do mesmo grupo causa empatia, um indivíduo do grupo muçulmano parece necessitar mais da ajuda já que está em um contexto cultural diferente do seu; (c) a situação social criada foi muito fortuita e não demandava que houvesse a geração de maiores sentimentos e condições de empatia com o experimentador. Esta última possibilidade explicativa ganha peso quando se compara o tipo de situação experimental apresentada nos relatos que têm demonstrado o efeito da categorização social sobre o comportamento de ajuda (M. Levine \& cols., 2005; Stürmer \& cols., 2006; Stürmer \& cols., 2005). Em tais estudos, a categorização tem sido manipulada experimentalmente, gerando sentimentos de pertencimento avaliados por meio de medidas de filiação ao grupo social.

Os resultados deste estudo indicam a necessidade de se avaliar melhor o efeito da categorização social como um fator antecedente de civilidade em situações urbanas. Isso poderia ser feito por meio do desenvolvimento de pesquisas que logrem realizar a mensuração da percepção daquele que precisa de ajuda como pertencente a outro grupo social e da atribuição da responsabilidade que o participante do experimento confere ao que necessita de ajuda. Uma das soluções para esse artefato metodológico seria o desenvolvimento de estudos com o uso de abordagem multimétodos, na qual os participantes não teriam apenas seu comportamento observado, mas também seriam entrevistados, antes ou após a observação do comportamento, sobre fatores determinantes do comportamento de ajuda.

De forma geral, o que se observa é uma possível prontidão prosocial dos brasileiros. Parece que o brasileiro é um povo atento a esse tipo de ocorrência. Quando se realiza uma variação de grupo social, há um aguçamento da curiosidade do sujeito, pois as taxas de ajuda para os indivíduos de trajes muçulmanos são ligeiramente maiores. De qualquer forma, os resultados deste trabalho são importantes para se abrir questões de uma agenda de pesquisa sobre o comportamento prosocial do brasileiro em diferentes situações sociais, indicando vários problemas de pesquisa que devem ser respondidos para a produção de conhecimento sobre a civilidade do brasileiro. É muito importante que as pesquisas sobre essa temática façam uso de múltiplas estratégias e abordagens metodológicas, de forma a estruturar modelos complexos de compreensão do fenômeno, considerando desde fatores intraindividuais até a observação do comportamento do indivíduo em longo prazo. Considera-se relevante, ainda, o uso desses experimentos para alimentar a discussão sobre teorias distintas na explicação desses comportamentos (Sagarin \& Lawler-Sagarin, 2005).

Como argumentado, considera-se que o comportamento prosocial é um tema atual e relevante, principalmente em um momento da história no qual se observa que os recursos para sobrevivência da humanidade começam a ficar escassos, 
dificultando a diminuição da distância social que existe entre os grupos humanos. Entender que fatores causam a conduta prosocial pode auxiliar no desenvolvimento de estratégias e políticas públicas que permitam um mundo mais igualitário e o uso parcimonioso dos recursos necessários para a vida em sociedade.

\section{Referências}

Almeida, A. C. (2007). A cabeça do brasileiro. Rio de Janeiro: Record.

Batson, C. D. (1998). Altruism and prosocial behavior. Em D. T. Gilbert, S. T. Fiske \& G. Lindzey (Eds.), The handbook of social psychology, Vol. 2 (pp. 282-316). New York: McGraw-Hill.

Batson, C. D., van Lange, P. A. M., Ahmad, N., \& Lishner, D. L. (2003). Altruism and helping behavior. In M. Hogg \& J. Cooper (Eds.), The SAGE handbook of social psychology, Vol. 1 (pp. 279295). London: SAGE.

Cialdini, R. B., \& Trost, M. R. (1998). Social influence: Social norms, conformity, and compliance. Em D. T. Gilbert, S. T. Fiske \& G. Lindzey (Eds.), The handbook of social psychology, Vol. 2 (pp. 151-192). New York: McGraw-Hill.

Dovidio, J. F., \& Penner, L. A. (2001). Helping and altruism. Em G. J. O. Fletcher \& M. S. Clark (Eds.), Blakwell handbook of social psychology: Interpersonal processes (pp. 162-195). Oxford: Blackwell.

Dovidio, J. F., Piliavin, J. A., Schroeder, D. A., \& Penner, L. A. (2006). The social psychology of prosocial behavior. New York: Lawrence Earlbaum.

Kemmelmeier, M., Jambor, E., \& Letner, J. (2006). Individualism and good works: Cultural variation in giving and volunteering across the united states. Journal of Cross-Cultural Psychology, 37, 327-344.

Knafo, A., Schwartz, S. H., \& Levine, R. V. (2009). Helping strangers is lower in embedded cultures. Journal of Cross-Cultural Psychology, 40, 875-879.

Levine, M., Prosser, A., Evans, D., \& Reicher, S. (2005). Identity and emergency intervention: How social group membership and inclusiveness of group boundaries shape helping behavior. Personality and Social Psychology Bulletin, 31, 443-453.

Levine, R. V., Martinez, T. S., Brase, G., \& Sorenson, K. (1994). Helping in 36 U.S. cities. Journal of Personality and Social Psychology, 67, 69-82.

Levine, R. V., Norenzayan, A., \& Philbrick, K. (2001). Crosscultural differences in helping strangers. Journal of Cross-Cultural Psychology, 32, 543-560.

Levine, R. V., Reysen, S., \& Ganz, E. (2008). The kindness of strangers revisited: A comparision of 24 US cities. Social Indicators Research, 85, 461-481.

Milgram, S. (1970). The experience of living in cities: Adaptations to urban overload and noise on behavior. Science, 167, 1461-1468.
Moser, G., \& Corroyer, D. (2001). Politeness in the urban environment: Is city life still synonymus with civility? Environment and Behavior, 33, 611-625.

Pearce, P. L., \& Amato, P. R. (1980). A taxonomy of helping: A multidimensional analysis. Social Psychology Quarterly, 43, 363-371.

Penner, L. A., Dovidio, J. F., Piliavin, J. A., \& Schroeder, D. A. (2005). Prosocial behavior: Multilevel perspective. Annual Review of Psychology, 56, 365-392.

Robbins, J. M., \& Krueger, J. M. (2005). Social projection to ingroups and outgroups: A review and meta-analysis. Personality and Social Psychology Review, 9, 32-47.

Sagarin, B. J., \& Lawler-Sagarin, K. A. (2005). Critically evaluating competing theories: An exercise based on Kitty Genovese murder. Teaching of Psychology, 32, 167-169.

Silva, A. V., \& Günther, H. (1999). Comportamento de ajuda no contexto urbano: um estudo experimental por meio do telefone. Psicologia: Teoria e Pesquisa, 15, 189-197.

Silva, A. V., \& Günther, H. (2001). Ajuda entre passageiros de ônibus. Estudos de Psicologia (Natal), 6, 75-82.

Silva, A. V., Günther, H., Lara, A. A., Cunha, L. F., \& Almeida, V. J. S. (1998). Técnicas da carta-perdida como instrumento de pesquisa social: Um estudo sobre preconceito e ajuda. Psicologia Reflexão e Crítica, 11, 1-12.

Stürmer, S., \& Snyder, M. (2010). The psychological study of group processes and intergroup relations in prosocial behavior: Past, Present, and Future. Em S. Stürmer \& M. Snyder (Eds.), The psychology of prosocial behavior (pp. 3-10). Oxford: WileyBlackwell.

Stürmer, S., Snyder, M., Krop, A., \& Siem, B. (2006). Empathymotivated helping: The moderating role of group membership. Personality and Social Psychology Bulletin, 32, 943-956.

Stürmer, S., Snyder, M., \& Omoto, A. M. (2005). Prosocial emotions and helping: The moderating role of group membership. Journal of Personality and Social Psychology, 88, 532-546.

Triandis, H. C., Marín, G., Lisansky, J., \& Betancourt, H. (1984). Simpatía as a cultural script of hipanics. Journal of Personality and Social Psychology, 47, 1363-1375.

Van de Vliert, E., Huang, X., \& Levine, R. V. (2004). National wealth and thermal climate as predictors of motives for volunteer work. Journal of Cross-Cultural Psychology, 35, 62-73.

Recebido em 30.05.2008

Primeira decisão editorial em 15.09.2008

Versão final em 15.10.2008

Aceito em 20.01.2009 